\title{
Avaliando o papel das qualificações na reforma educacional
}

\author{
Michael Young e Stephanie Allais ${ }^{1}$
}

Resumo

O objetivo deste Documento de Discussão é contribuir para o desenvolvimento de um quadro conceitual para a análise da reforma da qualificação em nível internacional. Este artigo tenta dar um passo atrás nas discussões e debates sobre os quadros de competências per se e pensar mais amplamente sobre o papel das competências na reforma educacional. Isto é importante porque o Projeto de Pesquisa dos Quadros de Competências da OIT busca ir muito além do que aquilo que já foi escrito sobre quadros de competências até agora, que consiste, principalmente, em descrições e reivindicações retóricas sobre o que os quadros de competências podem realizar. Nós buscamos desenvolver o entendimento desses quadros como mecanismos políticos os diferentes tipos que foram criados e implementados em diferentes países, a probabilidade deles atingirem seus objetivos e as experiências daqueles envolvidos em seus projetos e implementações. Este artigo vai fornecer um ponto de partida para se desenvolver uma análise e interpretação dos estudos de caso que serão

$1 \quad$ NT. Este artigo é o Docum ento para Debate apresentado pelos autores na reunião de 31 de março de 2009 do NQF Res earch (Pesquisa sobre os Quadros Nacionais de Qualificação) da OIT. Os autores autorizaram a publicação mediante solicitação de nosso colega Prof. Dr. Antônio Flávio B. Moreira, a quem a Comissão Editorial expressa sua gratidão. Em sua generosa concessão, Michael Young e Stephanie Allais solicitaram apenas que a tradução fosse cuidadosa e esperamos tê-los atendido a contento. Desta forma apresentamos algumas decisões que tomamos para a tradução e para a sua edição como artigo acadêmico. Há uma diferença entre o original recebido e o que está publicado. Logo após o prefácio de Christine Evans-Klock, o original apresentava a seção Purpose of this paper. Decidimos editar essa parte do texto e sua tradução como Abstract e Resumo do artigo. Também reduzimos o título completo do original (NQF Research: Discussion Document. Conceptualizng the role of qualfications in educational reform). Estamos seguros que ambas decisões respeitam as intenções dos autor es. Sobre os cuidados com a tradução o principal aviso aos leitores refere-se ao uso, pelos autores, da palavra qualifications. Optamos por verter, na maior parte das vezes, para competência quando o sentido referia-se às aptidões intelectuais e práticas e seu desenvolvimen to e aperfeiçoamento pelo processo de formação ou aos processos específicos de reforma educacional. E a traduzimos como qualificação quando o sentido era o reconhecimento formal da aquisição e desenvolvimento das mesmas com petências e sua certificação por instituições (à guisa de comparação, essas opções podem ser percebidas já na leitura do Resumo e do Abstract). Em outras expressões optamos ora por tradução literal, ora por compreensiva, sendo que em ambos casos a forma original é apresentada como nota de rodapé. 
conduzidos como parte da pesquisa da OIT. Esperamos que seja do interesse de todos aqueles envolvidos no Projeto e que possa lhes dar uma ideia de como estamos pensando sobre os quadros de competências, assim como contribuir para amplos debates sobre a reforma das qualificações.

\begin{abstract}
The purpose of this Discussion Document is to contribute to the developement of a conceptual framework for analyzing the reforns of qualifications internationally. The paper tries to take a step back fron the discussions and debates about qualifications frameworks per se, and to think more boradly about the role of qualifications in educational reform. This is important because the ILO Qualifications Frameworks Research Project ains to go beyond much that has beem written about qualifications frameworks up to now, wich consists largely od descriptions anf rethorical clains about the what qualifications frameworks can achieve. We ain to develop insights into qualifications frameworks as policy mechanisms - the differents types that have been designed and implemented in differents countries, the likelihood of their achieving their goals, and the experiences of those involved in their designs and implementation. This paper will provide a starting point for developing an analysis and interpretation of the case studies wich will be conducted as part of the ILO research. We hope it will be of interest to all those involved in the Project and give them an idea of how we are thinking about qualification frameworks as well as being a contribuition to wider debates about qualifications reform.
\end{abstract}


PREFÁCIO

Em todo o mundo, os governos estão tentando melhorar a qualidade da educação e capacitação oferecidas em seus países para, desse modo, melhorar os níveis de habilidades de sua força de trabalho - o que eles esperam que melhore as oportunidades para seus trabalhadores de obterem um trabalho decente e produtivo, além de melhorar a produtividade e a competitividade das empresas e da economia de um modo geral. Se a ênfase está em aumentar a relevância e a flexibilidade da educação e dos programas de formação, promovendo uma aprendizagem ao longo da vida, melhorando a transparência dos sistemas de qualificação, criando possibilidades para a acumulação e transferência de certificados ou desenvolvendo sistemas de garantia de qualidade, os governos tentam cada vez mais reformar seus sistemas de qualificação e transformam os quadros de competências em uma política para esta reforma.

Cerca de 70 países estão agora envolvidos de algum modo em realizar reformas por competências. Esses avanços são fortemente apoiados por várias organizações internacionais e agências bilaterais. Mas em que medida os quadros de competências são o melhor caminho para alcançar os objetivos desejados por essas políticas? Que outras estratégias da reforma por competências parecem estar funcionando bem? Que aproximações com os quadros de competências e suas estratégias de implementação são mais apropriadas, em quais contextos e para quais propósitos? Que nível de recursos (humanos e outros) pode ser necessário para alcançar os objetivos dessas políticas? O que é uma avaliação justa dos prováveis resultados? 
Para fornecer conselhos aos seus componentes, com base em uma analise de evidencias, a Organização Internacional do Trabalho (OIT) está promovendo um estudo comparativo sobre a implementação e o impacto dos quadros de competência em nível internacional, buscando inclusive as políticas necessárias e abordagens complementares.

Este é o primeiro de uma série de Documentos de Discussão produzidos a partir desse projeto, e serve para estimular o pensamento e o debate sobre as competências, além de contribuir para um quadro analítico para a pesquisa.

Christine Evans-Klock

Diretor de Qualificação e Empregabilidade ${ }^{2}$

\section{Introdução}

Um número crescente de países está introduzindo os quadros de competências ${ }^{3}$ como:

- Uma definição comum de competências em termos de resultados, que são tratadas independentemente das maneiras como foram obtidas;

- um conjunto de níveis comuns de descritores (normalmente de 8 a 12 para quadros que incluem todos os níveis de qualificação) e que se aplica em campos ocupacionais e de conhecimento

- e um conjunto integrado (normalmente de 12 a 15) de campos ocupacionais ou de conhecimento.

$2 \quad$ Director, Skills and Employability

3 NA: O termo quadro de competências, aqui, inclui os quadros de competências "parciais" concebidos para incluir apenas as qualificações vocacionais ou de ensino superior, assim como os "meta" quadros internacionais, como o Quadro Europeu de competências (QEQ). 
Uma série de objetivos educacionais, e mais amplamente sociais e políticos, está associada à introdução dos quadros de competências. Entretanto, as possíveis consequências da mudança dos sistemas de qualificação (que surgiram historicamente, e com freqüência $a d$ hoc) para os quadros de competência e para as abordagens por resultados que, normalmente, fazem parte desses quadros, têm sido consideradas mais do que provadas ou explícitas. Além disso, em toda a literatura sobre quadros de competências e suas aplicações, pouca atenção foi dada à natureza profunda da mudança para os diferentes grupos envolvidos - o Estado, os empregadores, os agentes educacionais e os estudantes. Desde a década de 1970 e os estudos seminais de Dore (1976) e Collins (1979), pouca tem sido a investigação sistemática sobre o papel das competências nos sistemas de educação e como isso pode estar mudando. Além disso, pouco se sabe sobre as possíveis consequências de fundamentar a concepção das competências nas declarações de resultados por escrito, que são independentes dos caminhos de aprendizagem que levam até elas.

\section{Os objetivos deste artigo são, portanto:}

- situar a reforma das competências em um contexto social e institucional mais amplo;

- propor uma forma de avaliar a mudança dos sistemas de qualificação, como eles surgiram historicamente, para os quadros de competências e as competências baseadas em resultados;

- e explorar as tensões que envolvem os diferentes objetivos que a introdução de um Quadro de competências (QC) ou um Quadro Nacional de Competências (QNC) pode alcançar. 
A difusão global dos quadros de competências ${ }^{4}$ não é um fenômeno isolado. Ela está diretamente ligada às mudanças associadas à globalização, em que as economias nacionais estão mais interdependentes do que nunca; e à migração da força de trabalho, que é uma experiência crescente e comum. "Globalização" é um termo usado para descrever tendências econômicas e políticas nos últimos trinta anos período no qual os quadros de competências surgiram. $\mathrm{O}$ termo se refere à tendência das economias nacionais de se tornarem interconectadas - e os governos nacionais têm menos controle sobre elas. Este conceito foi associado a um outro muito utilizado pelos cientistas sociais: neoliberalismo. Neoliberalismo é a ideia de que o mercado é a melhor maneira de distribuição de benefícios e serviços internacionalmente e, portanto, que o mercado deve ser intensificado e expandido para, se possível, todos os aspectos da vida humana (Fine 2002).

Nos últimos 30 anos, os governos têm promovido cada vez mais políticas que aumentam o papel do mercado (Harvey 2000; Bond 2005; Dumenil e Levy 2005). O que de melhor o Estado pode fazer para desempenhar o seu papel é ficar limitado à regulamentação e à melhoria das condições de circulação da informação, bem como contratar o setor privado para fornecer serviços essenciais nos lugares em que os mercados falhem (Palley 2005). A ênfase na reforma do setor público foi a desagregação das agências governamentais em pequenas unidades, que são constituídas como centros de custo e que se espera que possam competir entre si ou com instituições privadas contratadas pelo Estado em acordos semelhantes (Phillips, 1998). Declarações de desempenho são apresentadas como um mecanismo que vai estimular o crescimento de provedores de novos serviços, assim como permitir ao Estado avaliar a qualidade da oferta (Phillips 1998; Pollit 1998).

4 Qualifications frameworks. 
Essas tendências globais têm dado origem a toda uma nova abordagem à política educacional. Iniciativas de políticas específicas variam desde os sistemas de qualidade total e a utilização de objetivos e League Tables ${ }^{5}$ (como na Inglaterra) ao que um relatório recente do Centro Europeu para o Desenvolvimento da Formação Profissional (CEDEFOP) referiu-se como a "mudança para a aprendizagem por resultados"6 (CEDEFOP 2009), que é expressa, dentre outros aspectos, no surgimento dos Quadros Nacionais de competências (QNC). Esses desenvolvimentos tiveram origens e propósitos diferentes e propósitos em cada país. Às vezes, como na Inglaterra do governo Thatcher, eram explícitas as tentativas de abrir as instituições do setor público "ao mercado", ou fazer com que elas prestassem contas ao governo. Em outros casos, estavam mais preocupados com a coordenação e coerência ou em tentar forçar as instituições para alargar a participação. Apesar de uma diversidade de motivações originais é importante ter presente o que essas reformas têm em comum. Todas elas, em vários níveis, procuram limitar a autonomia das instituições como escolas e universidades e as tornam mais eficientes e eficazes por terem de competir umas com as outras - e todos procuram utilizar os resultados da aprendizagem para dirigir esta mudança. Uma vez que os resultados da qualificação são "desconectados" das instituições nas quais esses resultados foram obtidos, eles irão - afirma-se - ser mais flexíveis, mais portáteis e mais transparentes; e o reconhecimento e a certificação podem ser dados à aprendizagem informal ou em ambiente de trabalho. Como consequência, a educação formal é vista meramente como uma das muitas maneiras de se tornar qualificado.

Os governos têm cada vez mais tentado utilizar as competências como instrumentos para a reforma da educação e da formação, supondo que um quadro de competências vai elevar o número e a qualidade dos estudantes que se qualificam - por meio de,

5 NT: Sistema britânico de informação sobre a qualidade das escolas calculada a partir da pontuação dos estudantes em provas padronizadas.

$6 \quad$ Shift to learning outcomes. 
entre outras coisas, o encorajamento e a facilitação do "aprendizado ao longo da vida"7, reconhecendo a aprendizagem adquirida por meio da experiência e melhorando a articulação entre instituições de educação e o mercado de trabalho. A criação dos quadros de competências pode ser vista como uma resposta a uma "crise de legitimidade" dos atuais sistemas de qualificação. É uma estratégia de reforma preocupada em aumentar a flexibilidade e a transferência das qualificações e, indiretamente, em promover a competitividade econômica, a inclusão social e oportunidades educacionais.

O que está em jogo é o papel das instituições de ensino e de formação da próxima geração, o equilíbrio entre a aprendizagem formal e informal (em alguns casos no ambiente de trabalho) e a maneira pela qual a confiança nas competências é estabelecida e mantida. Nos países em vias de desenvolvimento, com recursos limitados e com poucas e frequentemente fracas instituições, a ideia de um quadro baseado em resultados para a certificação de toda aprendizagem parece especialmente atraente e as opções são particularmente agudas. Sob a pressão dos doadores e organizações internacionais, esses países são facilmente convencidos a desenvolverem quadros baseados em resultados - e, implicitamente, a concentrar menos sobre as instituições e no desenvolvimento profissional. No entanto, na medida em que há indícios de apoiar as reivindicações de tais quadros, esses paises interrompem a trajetória da experiência de desenvolvimento de suas instituições. Este projeto visa ajudar os países em desenvolvimento a enfrentar esse dilema. Este Documento de Discussão tem foco mais limitado: procura não apenas descrever o padrão emergente dos QNCs em todo o mundo, mas sim voltar atrás no debate sobre os diferentes tipos de QNC e levantar questões sobre: (1) qual o papel das É esse dilema que na reforma educacional; e (2) quão longe os resultados das competências, pelo menos se estão promovendo a aprendizagem, estão inelutavelmente ligados aos

$7 \quad$ Lifelong learning 
processos institucionais, por meio dos quais as pessoas adquirem habilidades e conhecimentos e tornam-se qualificadas. Ao questionarem a "mudança para resultados" descrita pelo CEDEFOP e os benefícios que ela alega oferecer aos países em vias de desenvolvimento, procura-se readmitir o papel crucial e legítimo das instituições - não somente escolas, faculdades e universidades, mas também associações profissionais, sindicatos e Câmaras de Comércio e Indústria - no processo de qualificação ou "de formação", como os franceses o chamam.

\section{Dois modelos de sistemas de qualificação}

Podemos identificar dois modelos (ou tipos ideais8) de como as competências operam na interface do usuario/fornecedor. Um deles é o modelo tradicional ou "institucional" (Young 2007, capítulo 8), no qual profissões e agentes educacionais têm uma autonomia e controle consideráveis sobre a qualificação. Isso não foi consequência de nenhuma intervenção governamental explícita, mas sim, da evolução das economias e da necessidade de trabalhadores com novas habilidades e conhecimentos que surgiu ao longo do tem po ${ }^{9}$. Como as qualificações expandiram-se no século XIX na Europa Ocidental, elas tenderam a ficar enraizadas nas instituições que as forneciam, e a confiança nelas estava muito ligada à confiança colocada nessas instituições. A insatisfação com o modelo "institucional" na nova conjuntura econômica dos anos 1980 levou ao que identificamos como o novo modelo de "resultado". Do ponto de vista dos governos, naquele momento, as qualificações na educação formal pareceram limitar:

8 NA: Usamos o termo modelo ou tipo ideal no sentido introduzido pelo sociólogo alemão Max Weber para capturar as distinções das mudanças recentes nas abordagens sobre as competências. Tipos ideais identificam tendências; eles não são descrições ou sistemas específicos, tampouco prescrições que estabelecem como as competências devem ser.

$9 \quad$ NA: Em algun s casos como na Alemanha, o Estado assumiu desde o início um papel cada vez mais poderoso na coordenação das qualific ações. 
- a oportunidade para os empregadores de tornar as qualificações mais próximas de suas necessidades;

- as oportunidades para os governos de intervenção e de trazer as qualificações mais para próximo de suas prioridades;

- o leque de áreas profissionais para as quais as qualificações estavam disponíveis;

- o leque de escolhas abertas aos estudantes em relação aos caminhos que tiveram de seguir para se tornarem qualificados, e que qualificações estavam disponíveis para eles.

Essas críticas das qualificações na educação formal podem ser resumidas no termo "captura pela oferta"10, que se tornou muito popular nos anos 1980 (Reggatt and Williams 1990). A ideia era que, como os fornecedores de educação ${ }^{11}$, mais do que os utilizadores, controlavam as qualificações e os caminhos para atingi-las, eles haviam "capturado" o mercado e, assim - como era argumentado -, criado ineficiências, impedido a entrada de novos atores.

O modelo de "resultados" - que apareceu pela primeira vez nos anos 1980 no Reino Unido e na Nova Zelândia - refere-se a um conjunto específico de políticas de intervenção concebidas com o intuito de levar essas críticas em consideração. Ao definirem as qualificações somente em termos de resultados pré-definidos, foi feita uma tentativa de transferir o equilíbrio de poder dos provedores e de grupos especializados - como as associações profissionais - para os usuários: governos, empregadores e estudantes. É esta mudança que foi incorporada na introdução dos quadros de qualificação baseados em resultados. Ainda que eles difiram consideravelmente nas maneiras pelas quais os resultados são utilizados (a ser discutido logo abaixo), muitos analistas sugerem que é praticamente impossível ter um quadro de qualificações que não seja baseado em resultados, apesar de haver

$10 \quad$ Provider capture.

11 Educational provider. 
exemplos contrários - por exemplo, o quadro australiano, como havia sido inicialmente introduzido. O impacto dessa mudança pode ser particularmente agudo para os fornecedores de educação, como era a intenção dos reformadores ${ }^{12}$. Ao invés de serem os principais definidores das qualificações, os fornecedores de educação são obrigados a verem a si próprios como os "vendedores" dos programas que levam à qualificação. A expectativa é a de que respondam, por um lado, às novas políticas governamentais; e, por outro lado, às necessidades expressas de empregadores e estudantes. A lógica desta tendência é o aparecimento de um "mercado de competências" em que as qualificações assumem cada vez mais a forma de "mercadorias", afastadas de qualquer relação direta com quaisquer dos programas de aprendizagem que estão ligados a elas ou das habilidades e conhecimentos para as quais elas atuam como "protocolos"13.

Um outro documento de discussão, que aparecerá depois neste projeto, incidirá sobre as diferenças entre a reforma na qualificação de estados "fortes" e "fracos". Entretanto, por enquanto, o que deve se levar em conta é que uma reforma que se projeta como um desafio para as instituições e fornecedores de ensino é provável que venha a ter um efeito radicalmente diferente em países onde essas instituições são fracas ou inexistentes.

A passagem de um modelo "institucional" para um modelo por "resultados" das qualificações representa uma mudança na forma como as competências requerem a confiança da sociedade. No modelo "institucional”, as qualificações são conhecimentos baseados em domínio de conhecimentos e estão integradas às instituições; a confiança está situada em pessoas com conhecimentos especializados,

12 NA: A lógica por detrás desta mudança varia consideravelmente. No Reino Unido, por exemplo, resultou nas políticas neoliberais do governo Tatcher (e, mais tarde, do Novo Trabalhismo), que pretendia promover a competitividade econômica pela transferência do poder sobre as qualificações para as entidades patronais (Wolf 2002).

13 Proxies 
nas associações profissionais, nos vínculos entre professores e os produtores de conhecimentos especializados nos diferentes domínios e nas instituições em que os programas de estudo, que levam às qualificações, estão localizados. O modelo surgiu no século XIX - no que são agora os países desenvolvidos -, quando as profissões e os campos de conhecimentos eram relativamente estáticos ou mudavam apenas de acordo com pequenos incrementos. As qualificações, em um modelo "institucional", impõem limites ao número de decisões abertas aos estudantes quando eles decidem quais qualificações pretendem obter. Além disso, eles presumem que é a atual organização do conhecimento, como expressa no currículo das instituições e nos exames por associações profissionais, que definem a distribuição de acesso, os requisitos para ingressar em um programa e os critérios para ser reconhecido como qualificado. Em uma sociedade relativamente estática, essas restrições eram tomadas como dadas e quase não se reparava nisso. Confiança nas qualificações era poder contar com a tradição e a experiência - ambas facilitadas graças ao fato da qualificação só ser obtida por uma minoria e terem se tornado um fenômeno mais elitista. Desafios a este modelo apareceram em diferentes países, de maneiras distintas e por diferentes razões. Na África do Sul, por exemplo, estavam associados ao fim do apartheid; no Reino Unido, em resposta ao aumento do desemprego dos jovens e, na Nova Zelândia, com a perda de mercados de seus produtos agrícolas e a crise na competitividade econômica de suas indústrias. Mais recentemente, esses desafios se alastraram para os países em desenvolvimento, com oferta de educação e de formação relativamente limitadas, mas que estão enfrentando as exigências comuns da competitividade econômica global. Um consenso global entre os formuladores de políticas - aos quais Grubb e Lazerson (2006) referem-se como o evangelho da profissionalização ${ }^{14}$-, não só percebeu o fracasso das faculdades e universidades e enfatizou a necessidade de reformá-las com objetivos econômicos, mas sublinhou a importância econômica da aprendizagem não formal, da informal e

$14 \quad$ Vocational gospel 
por experiência, e a certificação dessas competências baseadas em resultados como o principal instrumento de política.

Isso deu origem a um desafio ao direito tradicional das profissões e de outros especialistas para definir o que é ser "qualificado". Também surgiu em resposta ao conservadorismo ${ }^{15}$ inerente das instituições de ensino e a sua tendência para limitar o acesso aos novos estudantes e para resistir ao desenvolvimento das qualificações para além das fronteiras dos domínios. A alternativa que apareceu é a do modelo 'baseado em resultados', no qual as competências são especificadas em termos de 'resultados' que não impõem constrangimentos sobre como ou onde os estudantes tornaram-se qualificados, e não estabelece regras para apropriação de conteúdos; apenas os critérios referidos por meio dos resultados devem ser cumpridos. A abordagem baseada em resultados é concebida para transferir o poder das instituições e do domínio de especialistas, invocando uma lista genérica de resultados ou critérios para definir o que é uma competência (geralmente em termos de vários tipos de competências e capacidades) e os níveis em que a qualificação pode ser atingida. Esses últimos critérios, conhecidos na documentação do quadro de qualificações como 'descritores de níveis', a gradação das habilidades sociais e cognitivas por meio de disciplinas de conhecimento e campos profissionais. Dessa maneira, a abordagem baseada em resultados subordina o conteúdo dos conhecimentos especializados e as diferenças entre os diferentes domínios a critérios genéricos. Ela retira as qualificações das instituições - que devem, então, 'vender' seus programas de aprendizagem para os estudantes, como caminhos a percorrer para atingirem as qualificações. Afirma ainda dar oportunidades a estudantes para a obtenção de competências ao submeterem suas experiências para avaliação

15 NA: É im portante deixar claro que cons ervadorismo pode ter duas ac epções muito diferentes no que diz respeito às instituições de ensino: pode remeter a um fator quase inerente a todas as instituições de ensino, que 'transmitem conhecimento' de uma geração para outra; e pode tam bém remeter para a tendência de instituições como colégios e universidades que preservam as vantagens e os privilégios de grupos sociais particulares (Young 2009). 
(Reconhecimento do Aprendizado pela Experiência [APEL]) sem terem participado de nenhum curso ou estudo formal.

Entretanto, como mencionado anteriormente, ainda que muitos países estejam mudando em direção aos quadros de competências baseados em resultados (CEDEFOP 2009), o conceito de uma 'aprendizagem por resultados' é muito geral ${ }^{16} \mathrm{e}$ pode ser interpretado de várias maneiras. Não é surpresa, portanto, que nem todos os quadros nacionais de competências usem o conceito de 'resultados' da mesma maneira. Em alguns países, o modelo 'de resultados' 'puro' pode ser adotado e as competências são definidas, independentemente das suas ligações a quaisquer dados ou instituições específicas. O Quadro Nacional de Competências da África do Sul foi originalmente pensado desta maneira (Allais 2007). Outros, como o Quadro Escocês de certificação e qualificações [SCQF], podem usar a ideia de resultados, mas adotam uma proposta de qualificações que tem mais em comum com o modelo 'institucional', ainda que com mais flexibilidade de escolha disponível para os estudantes. Em outras palavras, o fato de um país declarar que está usando aprendizagem por resultados não significa necessariamente que esteja removendo completamente as qualificações das instituições ou subordinando completamente as diferenças entre os domínios de conhecimento aos relatórios genéricos de resultados. Essas diferenças na utilização da ideia dos resultados está bem ilustrada no contraste entre a Alemanha e o Reino Unido. Na primeira, os resultados são definidos em relação à 'competência profissional' e as qualificações envolvem necessariamente dados; já no Reino Unido, pelo contrário (no caso das Qualificações Vocacionais Nacionais (NVQs), os resultados são definidos mais estritamente em termos de tarefas de trabalho. Essa diferença não só cria problemas de comparação internacional, mas tem implicações diferentes para a organização de programas

16 NA: CEDEFOP (2008) define 'aprendizagem por resultados' [learning outcomes] como "relatórios sobre o que o estudante sabe, compreende e é capaz de fazer após a conclusão da aprendizagem". 
educativos e para o papel da aprendizagem fora do trabalho. O alargamento da competência profissional que se vê em países que seguem a tradição alemã mantém a importância da confiança em comunidades profissionais especializadas, e porque a progressão é parte integrante da ideia de uma ocupação, dá um papel explicito às instituições de ensino na concepção da aprendizagem fora do trabalho (Brockmann, Clarke e Winch, 2008).

Assim, por um lado, parece haver um deslocamento global para a aprendizagem por resultados como uma abordagem para mudar a forma pelas quais as competências operam; por outro lado, existem diferenças significativas nas formas como os resultados são compreendidos e utilizados nos diferentes países. O que parece ser comum (além da utilização do mesmo termo) é a tentativa de transferir o poder das instituições de ensino. O que difere é a extensão e a natureza dessa mudança, a força e a natureza das instituições dos diferentes países, e até onde os resultados são tratados literalmente independentes de qualquer programa específico ou simplesmente como uma maneira de demonstrar os objetivos desses programas. No entanto, a introdução dos quadros de competências pode ser definida em termos da passagem de um modelo de domínio - conhecimentos específicos e programas oferecidos por instituições específicas - para um critério, ou um modelo baseado em resultados. Isso levanta uma série de questões que os países que estão introduzindo os quadros de competências têm de enfrentar. Aqui, vamos discutir o seguinte:

- estabelecer a necessária confiança nas competências pelos diferentes usuários;

- resolver as tensões entre governos, buscando usar as competências como 'orientadores da reforma': os empresários querendo utilizá-las como 'imperativas' no recrutamento; os estudantes usando-as para o progresso na empregabilidade e na educação; e os fornecedores de educação usando-as como guias para desenvolver seus programas de curso; 
- as implicações da mudança de basear as qualificações de domínio específico para critérios genéricos;

- até que ponto as competências baseadas em resultados podem ser usadas para promover, simultaneamente, o desenvolvimento de habilidades, bem como o de equidade e acesso;

- a possibilidade de que, para os países com instituições educacionais fracas, uma política concebida em países mais ricos, para transferir o poder de suas instituições - que são vistas como demasiado dominadoras - possa, na verdade, promover maior enfraquecimento de seus sistemas educacionais.

Todas essas questões vão ser expressas de maneiras distintas nos diferentes contextos nacionais e nos diversos modelos de quadros de competências. Um dos objetivos deste projeto é o de explorar a medida em que os países adotam os quadros de qualificações com diferentes combinações das duas abordagens de qualificações e as implicações dessas diferenças.

\section{Competências e confiança}

As competências surgiram na maior parte dos países com pelo menos um consenso tácito sobre o que eram. A definição de qualificações por meio de aprendizagem por resultados e a criação dos quadros de competências são tentativas explícitas de desafiar este consenso e, em particular, de desafiar o poderoso papel das instituições estabelecidas - especialmente o dos provedores de educação e o das associações profissionais. No entanto, o processo de transferência de confiança para as competências e longe das instituições pode retirar a base da confiança dos usuários nas qualificações. 
Uma competência é sempre, de alguma forma, um protocolo do que um estudante sabe e pode fazer. Pelo fato de ser uma 'moeda'17 que o titular pode levar para além da instituição onde a adquiriu - e onde os professores e instrutores sabem perfeitamente o que o estudante sabe e pode fazer -, a competência é um símbolo que faz a mediação entre as instituições de ensino e entre estas e o mercado de trabalho. Uma das razões pelas quais os governos querem introduzir os quadros de competências baseados em resultados é para superar a falta de confiança que eles têm nas instituições que fornecem os programas que levam às qualificações (e que se presume que sejam compartilhadas por empregadores e alguns estudantes). Esta falta de confiança é passível de ser um problema particular no caso daqueles que saem de um país para outro, quando a instituição na qual a qualificação foi obtida pode não ser conhecida fora do país. Outra possibilidade é que a confiança nas instituições que conduzem às qualificações foi abalada dentro do próprio país, como é o caso da África do Sul do apartheid.

Em geral, quanto mais mobilidade têm as pessoas dentro e entre os estados nacionais e quanto mais complexa é a sociedade, menos as pessoas podem crer nos contatos cara a cara e na familiaridade com instituições particulares como base para a confiança; daí o estabelecimento de uma base alternativa para a confiança se tornar um fator determinante para a credibilidade das novas competências; não há substituto. As competências que não possuem confiabilidade dos usuários estratégicos não serão utilizadas ou serão ultrapassadas, como se pode ver a partir dos exemplos dos NVQs do Reino Unido. Quadros de qualificação apresentam relatórios de resultados precisamente expressos como uma base alternativa para a confiança - a alegação é que porque a competência é baseada em resultados, ela representará uma boa descrição do que o portador é qualificado para fazer. O que

17 Currency é o primeiro elemento de um aparente jogo de palavras que se completará, mais adiante, com Token, que vertemos como "simbolo". Havia também a possibilidade de versão para capital/moeda, abandonada por parecer exagerada. 
levanta duas questões: a primeira é em que medida dos relatórios de resutados que não estão relacionados a programas de aprendizagem podem ser confiáveis (ou, na verdade, não dizer nada a seu favor); a segunda é saber qual vai ser a nova base de confiança, se as fontes tradicionais de confiança são vistas pelos governos como muito poderosas e distorcem as competências, longe das necessidades reais das economias modernas. A literatura refere-se, de maneira não específica, a uma 'comunidades de confiança' (Coles 2007) e 'comunidades de práticas' (CEDEFOP 2008/CEDFOP 2008). No entanto, com o enfraquecimento dos requisitos de conteúdo relacionados com os campos de conhecimentos específicos e profissões - o que é uma consequência da ênfase dada nos resultados -, é difícil saber em que as novas 'comunidades de confiança' serão baseadas. Além do mais, os resultados, para que possam ser específicos, tornaram-se comumente estreitos e podem, por isso mesmo, minimizar a aprendizagem que é avaliada. A experiência de sistemas de ensino superior que adotaram os quadros baseados em competências ${ }^{18}$, como a Escócia (Gallagher 2005), sugere que nas universidades mais importantes elas estão associadas à persistência das antigas formas de confiança. Pode ser por isso que a introdução de um quadro de competências - enquanto a abertura de acesso a alguns que antes eram excluídos -, poderia conduzir a um sistema mais dividido. Nos lugares em que as competências têm uma base de confiança estabelecida geralmente nas universidades e em escolas elitistas -, esse modelo é mantido e pouca atenção é dada aos resultados. Por outro lado, as competências baseadas em resultados que não têm bases de confiança estabelecidas não serão valorizadas, o que poderá conduzir a novas desigualdades.

$18 \quad$ Outcomes-based fram eworks 


\section{Competências como orientadoras da reforma e como mediadoras}

As competências surgiram nas sociedades como mediadoras; esta é a razão pela qual elas existem, como protocolos ou atalhos para o que alguém sabe e pode fazer. No entanto, ao introduzirem os quadros de competências baseados em resultados, os governos começaram a usá-las, invariavelmente, para alcançar um conjunto mais amplo de objetivos políticos e sociais, como melhorar a qualidade (e a relevância), bem como a quantidade de educação fornecida em seus países, para oferecer possibilidades de certificação baseadas na aprendizagem não formal, e assim por diante. A separação dos 'resultados' (obtidos nas qualificações) do 'oferecido' 19 - como os conteúdos, o ensino, e vários outros aspectos das instituições de ensino -, parece ser um mecanismo para isso. Mas, uma vez que as competências foram separadas das instituições, uma questão aparece: serão as primeiras capazes de mediar o conflito entre as instituições e o mercado de trabalho? Como elas podem fazer isso, se elas não estão nem inseridas nas instituições, nem se originam destas? Se as competências são mediadoras entre instituições educacionais e o mercado de trabalho elas precisam possuir uma relação com as instituições educacionais. A maioria dos documentos sobre os quadros de competências baseados em resultados afirmam que elas vão melhorar a maneira pela qual as competências são compreendidas no mercado de trabalho, especialmente pelos empregadores. Eles afirmam também que se os empregadores estão diretamente envolvidos na definição de resultados - e, portanto, como o que se aprendeu no processo de obtenção da competência -, elas serão mais úteis para eles e mais pessoas se tornarão qualificadas. É por isso que a introdução de um quadro baseado em resultados especialmente para qualificações profissionais - é visto por vários governos como uma oportunidade para aumentar o papel dos empregadores e reduzir o papel dos

19 Inputs. A versão por "oferecido" foi a melhor forma encontrada para expressar a idéia envolvida, a formação nas instiuições concebida a partir da polaridade input/outcomes. Nas demais partes do texto em que os autores utilizam apenas "inputs", mas em alusão à essa polaridade, mantivemos a versão para "ofer ecidos". 
fornecedores de serviços de educação e de treinamento. Mas, uma vez que o papel desses últimos tem sido reduzido, é de se questionar se, de fato, as competências servirão como mediadoras entre eles e o mercado de trabalho. Em outras palavras, tentar utilizar as competências baseadas em resultados como orientadores de outros objetivos educacionais e econômicos pode reduzir a efetividade das competências em atuarem no papel necessário de mediação entre educação e o mercado de trabalho ainda que a melhora da comunicação entre educadores e empregadores seja um dos objetivos expressos dos quadros de competências.

Porque as competências baseadas em resultados não se referem às atividades das instituições de ensino, é mais difícil que as competências cumpram esse papel de mediador entre as instituições e o mundo do trabalho. No quadro baseado em resultados, a confiança na qualificação reside assumidamente na especificidade dos resultados, que pretendem definir o que um estudante sabe e pode fazer. Isso dá origem a dois problemas: se os resultados não estão conectados com as atividades com as quais o portador ocupou-se durante seus estudos, eles precisam ser exatos ao definir o que ele/ela sabe e pode fazer. No entanto, a pressão para uma maior especificida de leva inevitavelmente a uma diminuição dos resultados e à banalização de sua avaliação - isto é, por vezes, indicado como 'múltipla escolha'. Se os resultados são considerados como ligados às atividades que o portador efetuou durante o estudo, o que mais se pode ganhar com a designação dos resultados independentes dos programas de aprendizagem? Ainda que uma vasta documentação sobre quadros de competências afirme que os resultados de aprendizagem podem proporcionar uma linguagem de 'tradução', para além das fronteiras nacionais, ou entre o local de trabalho e as instituições de ensino, não está claro, o que isso significa na prática. Além disso, apesar dos resultados de aprendizagem estarem explicitamente especificados, a competência pode ser somente um protocolo; ela nunca pode resumir tudo que o portador sabe, tudo o que é necessário para realizar uma tarefa ou ser aceito como um membro 'qualificado' de 
uma ocupação; a questão da confiança, e de suas bases, discutida anteriormente neste artigo permanecem. Se a competência se refere à aprendizagem que se deu na instituição, assim como aos resultados dessa aprendizagem, é mais provável que ela atue como um protocolo para a aprendizagem e, consequentemente, como mediadora entre a aprendizagem que teve lugar na instituição e os conhecimentos e habilidades necessários para o mundo do trabalho. Se a competência não está inserida na instituição, então a única evidência disponível para os empregadores ou outros utilizadores são os próprios resultados da aprendizagem. A questão passa a ser sobre qual base os empregadores e outros utilizadores podem confiar nos resultados. Estes não são autoevidentes, nem constituem uma base de confiança em si mesmos. Universidades em vários países estão agora à espera de relatar os resultados ${ }^{20}$ daqueles que tenham obtido esses graus ${ }^{21}$. É provável, entretanto, que não seja a declaração dos resultados que garanta a qualidade do grau, mas a confiança depositada pelo usuário na universidade - que está conectada a uma noção maior do status e da reputação da mesma.

Além disso, a estratégia de colocar os empregadores para conduzirem a reforma do sistema educativo por meio de seu envolvimento no estabelecimento dos resultados de aprendizagem cria outros problemas. Nem todos os empregadores querem estar envolvidos; eles ou esperam que o sistema de educação lhes forneça um pessoal qualificado ou, em outros casos, se contentam em empregar pessoas sem qualificação. Para aumentar o envolvimento do empregador ao nível existente, por exemplo, no sistema dual da Alemanha ${ }^{22}$, é provável que seja necessário um

20 To state the outcomes, na continuação do texto os autores, a partir dessa idéia, recorrerão com frequência a expressão "written outcomes" que vertemos ora por Relatórios, ora por Declaração de Resultados.

$21 \quad$ Degrees

22 NT: No sistema dual da Alemanha há, desde os seus primór dios, uma forte integração entre as escolas de formação profissional e o aparelho produtivo em que essas qualificações serão exercitadas. 
conjunto mais vasto de alterações do que apenas a qualificação expressa como ‘declaração de resultados’.

Quando as qualificações são associadas às instituições, estudantes e estagiários em programas vocacionais e profissionais são avaliados pela instituição e fazem suas próprias conexões entre o que estão aprendendo e o que têm de fazer no trabalho. Os empregadores julgam os portadores de competências com base em suas experiências prévias com estudantes e professores, de sua perícia profissional e seu conhecimento daquilo que necessita em termos de concepção, ensino e avaliação de programas. É a este tipo de conjunto de processos que nos referimos quando falamos da ideia da competência ter um papel de mediadora. No caso das competências baseadas em resultados, está mais do que claro como os resultados fazem, na prática, a mediação das atividades dos empregadores, professores e alunos e qual o papel real que os resultados desempenham. Esperamos que no curso deste projeto tenhamos algumas provas sobre esses processos, e o quanto, nesse sistema que se assenta inteiramente sobre os resultados, os utilizadores continuam a confiar nas qualificações com base nos programas que eles presume que o portador da competência deve ter obtido; em outras palavras, os sistemas baseados em resultados ainda são fundamentados em suposições tácitas sobre as instituições?

Nas abordagens baseadas em instituições, as competências mediam o acesso ao conhecimento em domínios especializados por meio de professores especialistas. Os países variam de acordo com que corporação (as instituições de ensino ou corporações separadas) tem a responsabilidade de definir e marcar os exames que conduzam à qualificação. Em um quadro baseado em resultados em que não haja conexões explícitas entre competências e instituições educacionais, os resulta dos são avaliados por um assessor, em termos de 'desempenho de tarefas'. No entanto, essa abordagem pressupõe que o conhecimento em dominios especializados pode ser inferido a partir de evidencias de desempenho [performance]. Muitas das críticas aos 
modelos baseados em resultados ou em competências, feitas tanto pelos acadêmicos como pelos empregadores, põe seu foco exatamente nesta hipótese. Uma possível consequência desta abordagem é que o conhecimento poderoso ${ }^{23}$ - que leva as pessoas além de suas experiências e locais específicos de trabalho e que, por isso mesmo, constitui uma base de progressão -, torne-se cada vez menos importante na obtenção de uma competência. A menos que a questão do conhecimento poderoso e do acesso a ele seja levantada, é provável que os quadros de qualificação sigam o caminho dos NVQs no Reino Unido e que não escapem à crítica - de que eles fazem pouco mais do que proporcionar um baixo nível de qualificação para os postos de trabalho com exigências mínimas e, ao mesmo tempo, oferecem oportunidades mínimas de progressão. Este projeto tenta entender a extensão daquilo que está acontecendo ou que provavelmente vai acontecer nos diversos países que estão introduzindo os quadros de qualificações.

Como discutido acima, a utilização das qualificações como instrumentos da reforma educacional dos governos visa melhorar o seu papel de mediadoras, tornando mais explícito o que o portador da competência sabe e pode fazer e, ao mesmo tempo, dando mais ênfase nos usuários do que aos fornecedores, para definir o que está incluído na competência. No caso particular das qualificações profissionais, os governos esperam que, especificando as competências em termos de resultados que podem ser expressos por meio de tarefas de trabalho, os empregadores irão encontrar mais facilidade de influenciar nessas competências, desenvolver um senso de propriedade destas como contribuidoras para a rentabilidade e, consequentemente, aumentar os níveis de qualificação de seus trabalhadores.

$23 \quad$ Powerfull knowledge. NA: Este termo (Young 2009) corresponde ao conhecimento que é a base para explanações confiáveis e alternativas de analise. Ele é expresso de maneira conceitual, ao invés de uma forma prática, e é frequentem ente - mas não nec essariam ente - associado à ciência e à tecnologia. NT: Embora nossa opção inicial tenha sido "conhecimento fortalecedor", acompanhamos outras traduções para o português que optaram por "conhecimento poderoso", que o próprio M. Young estabelece em oposição ao "conhecimento do poderoso". 
A ideia de usar a 'aprendizagem por resultados' é a de que, ao invés dos empregadores escolherem a partir de pessoas que têm qualificações provenientes de uma série de diferentes instituições de ensino e de programas, eles esperam especificar a essas instituições que resultados seus programas devem obter. Mas, uma coisa é garantir que os programas de aprendizagem levem em consideração as necessidades dos empregadores; outra, bem diferente, é imaginar que essas demandas podem ser adequadamente expressas pela 'aprendizagem por resultados'. Em primeiro lugar, os empregadores em qualquer setor industrial ou de serviços, variam imensamente: em termos de tamanho, de como seus serviços ou produção são organizados, e nas suas exigências por conhecimentos e habilidades. Não há apenas uma 'visão empresarial' das competências, mesmo em um setor específico; em segundo lugar, enquanto os empregadores podem deixar claro suas necessidades imediatas, é pouco provável que eles tenham o conhecimento de prever suas necessidades futuras, como assinalou a OIT (2008). A concepção e o desenvolvimento das competências e dos currículos não pode se assentar somente na evidência das necessidades atuais dos empregadores; por serem inevitavelmente baseadas no cotidiano de seus locais de trabalho. A concepção das competências vai envolver o julgamento de especialistas que levem em consideração uma série de fatores, incluindo o provável desenvolvimento das indústrias e dos serviços e as necessidades atuais dos empregadores, tanto quanto o que a competência oferece como base para a aprendizagem posterior. Em terceiro lugar, quando os empregadores são consultados para expressarem suas necessidades, eles terão certamente uma série de desejos que, em muitos casos, ultrapassam a capacidade das instituições de ensino e que não levam em consideração (e não têm conhecimento disso) o que na realidade é levar as pessoas a dominar as habilidades e conhecimentos necessários a uma determinada profissão. Isso não implica que não haja um compromisso entre a indústria e locais de trabalho, de um lado, e as instituições de ensino, do outro; implica, sim, que o primeiro não deve ser visto como o único condutor dos sistemas vocacionais de educação. 
Governos esperam ainda que, ao demonstrarem as competências como resultados, eles encorajem mais empregados e àqueles que buscam emprego a obter qualificações, sobretudo porque se considera que a utilização dos resultados da aprendizagem abre possibilidades para a acumulação de certificados e transferência das certificações da aprendizagem pela experiência. Apesar das muitas alegações em contrário, há muito poucas provas que essas esperanças sejam concretizadas particularmente no que se refere à transferência das certificações de aprendizagem entre as qualificações. Há poucas provas que a acumulação de certificados e seus modelos de transferência funcionem efetivamente. Não menos importante é que, quanto mais os estudantes se identificam com a possibilidade de obter competências pela acumulação de certificados e sua transferência, menos estão suscetíveis a serem convencidas do valor da aprendizagem em uma determinada área. Portanto, se o esquema de transferência de certificados realmente funciona, é possível que eles levem a consequências imprevistas e indesejáveis. Por exemplo, uma consequência possível de se dar menos ênfase no que muitas vezes é entendido como aprendizagem 'linear' é que as vias alternativas à qualificação pela 'transferência de certificados' podem parecer mais fáceis e poucos vão optar pela via que constitui a base mais provável para que eles progridam aos níveis superiores; a longo prazo, isso pode significar que os empregadores encontrem-se pior do que antes no que diz respeito à busca de candidatos devidamente qualificados.

\section{Do conhecimento por domínios às competências por critérios}

Os quadros de competências refletem uma mudança no equilíbrio das diferenças entre domínios, entre qualificações profissionais e acadêmicas, e entre os tipos de aprendizagem (em casa, no local de trabalho, na escola ou na universidade) há similaridades. Esta tendência em direção aos critérios genéricos para todas as competências é comumente apresentada como justa e sustentando o alargamento da 
participação e da aprendizagem ao longo da vida. Mais importante do que esses objetivos, é importante levantar questões sobre até onde a qualidade do ensino pode ser garantida sem se estipular um conteúdo que é específico para diferentes setores de atividade e sem reconhecer que as oportunidades de aprendizagem na universidade são diferentes e não podem ser tratadas da mesma forma que aquelas oferecidas pelos locais de trabalho vice-versa. Um fator determinante pode ser como as competências e os currículos estão relacionados em sistemas específicos de educação e treinamento. A experiência dos primeiros quadros de competências como as dos NVQs no Reino Unido (West 2004) - sugerem que as competências baseadas em resultados são provenientes de uma análise funcional do desempenho no trabalho e não podem ser a base para inferir ou "planejar" currículos. Se isto é reconhecido, então as competências por resultados podem ter um papel mais apropriado de amplas orientações curriculares, que 'desenhadas por corpos de especialistas de conhecimento' e, como eles estão melhor controlados, selecionados e sequenciados, para os estudantes com diferentes níveis de aquisições anteriores. Se, por outro lado, as competências por resultados são usadas como fonte primaria para a concepção de currículos, o mais provável é que as competências neguem o acesso dos estudantes ao 'conhecimento poderoso' (Young 2009) de que eles necessitam para o progresso na educação e no emprego.

Mesmo que os relatórios de resultados sejam escritos independentemente de qualquer programa de aprendizagem que possam produzi-los, os empregadores e outros usuários ainda vão tratá-las como protocolos para as atividades que eles presumem que os portadores já tenham realizado na instituição de ensino; esta é a única base objetiva que eles têm para confiar nas competências. A lógica deste argumento é a de que é preferível tornar explícito o papel das instituições nas competências a deixá-lo implícito, como é feito se as competências forem definidas independentemente do oferecido pelas instituições. Além do mais, ao dar às instituições um papel de destaque, os usuários estão aceitando que a especialização 
de professores é real e que isso lhes dá uma base para tomada de decisões sobre a concepção dos currículos e as competências que outros não estão em posição de fazer. As instituições de ensino não são apenas vendedoras dos seus bens - no caso delas, as competências - em um mercado.

\section{Tensões nos objetivos na reforma por competências}

A maioria das declarações dos governos sobre os quadros de competências identificam como importantes dois tipos de objetivos bem diferentes - de um lado, o seu próprio papel no apoio ao desenvolvimento de habilidades e da competitividade econômica; e, de outro, o papel deles na promoção da equidade, justiça social e inclusão social. Um sem número de hipóteses que não foram examinadas são de que esses dois objetivos são diretamente compatíveis. Parece haver duas razões possíveis do porquê dessas hipóteses terem sido presumidas e tão pouco examinadas; uma é que porque ambos os conjuntos de objetivos são amplamente sustentados, eles devem ser atingíveis por meios semelhantes - neste caso, introduzindo-se um quadro de competência; a outra é que, na medida em que talvez haja uma tensão entre os dois objetivos, eles representam amplamente o compromisso político aceito entre 'esquerda' e 'direita', sob a bandeira de uma aproximação da modernização geral da reforma educacional. Em outras palavras, enquanto a 'esquerda' está sendo 'realista' sobre aceitar a importância da competitividade econômica, a 'direita' está sendo 'compassiva' no que diz respeito à importância da justiça social. Porém, apesar do aparente compromisso, se este projeto é para ajudar os países a tomarem melhores decisões sobre suas reformas da educação e da formação, vale a pena sondar mais a fundo as possíveis tensões entre esses dois conjuntos de objetivos. Além disso, mesmo que eles representem aspectos de uma agenda política comum que é amplamente aceita, eles representam interpretações muito diferentes desta mesma agenda, com implicações para a reforma da educação e da formação muito diferentes também. Sem tornar essas diferenças explícitas, os países em 
desenvolvimento, em particular, não terão a melhor base para evitar os erros cometidos pelos países 'que começaram antes' a introdução dos quadros de competências - como a Inglaterra e a Nova Zelândia.

A questão, como apontou o sociólogo Johan Muller (2000), é que quadros de competências representam um tipo de mistura híbrida de duas ideias bastante diferentes sobre como os seres humanos aprendem e sobre como a ideia de competência é interpretada. Uma ideia que surgiu nas políticas centradas nas crianças dos anos 1960 e que pode remontar à Rousseau é a de que todos os seres humanos nasceram com uma espécie de competência comum e universal, que é compreendida a partir de desempenhos muito diversos - que dependem, por sua vez, da família e da sociedade onde nascemos. Essa ideia está expressa nas hipóteses centradas na aprendizagem, nas quais os quadros de competências são baseados, e na equidade das oportunidades e no alargamento da participação que alguns consideram que eles vão conduzir. Por serem abertos a todos, no que diz respeito às conquistas educacionais prévias, e por incluírem todos os níveis de aprendizagem, do mais elementar ao superior, os quadros de competências supõem que, pelo menos em princípio, que qualquer um pode alcançar qualquer nível, a não ser que seja constrangido pelas circunstâncias. Isso contribui para a popularidade dos quadros de competências entre educadores de adultos e a aprovação do seu papel no Reconhecimento do Aprendizado pela Experiência (APEL), e o Reconhecimento de Aprendizagem Prévio (RPL)

No entanto, os quadros de competências tornaram-se populares em um momento específico da história e por razões específicas e, desta maneira, não é surpresa que suas origens e as oportunidades que eles alegam oferecer sejam menos do que universais. Os objetivos da portabilidade e da flexibilidade das competências ligados às necessidades dos empregados e dos desempregados de estarem sempre abertos para serem requalificados (o aspecto econômico da aprendizagem para a 
vida) - são vistos não apenas como direitos universais, mas associados às ideias pósfordistas sobre as mudanças econômicas que tiveram lugar nas sociedades industriais.

Esses dois conjuntos de objetivos para os quadros de competências tendem a ser baseados em hipóteses pedagógicas e curriculares diferentes. A ideia 'psicológica' de competência implica que todos os estudantes possam alcançar seus potenciais se eles estão livres dos empecilhos que inibem suas capacidades 'naturais' de aprendizagem ${ }^{24}$. Neste cenário, espera-se que os professores atuem desempenhando um papel sutil, porém emancipador, como 'facilitadores' e avaliadores da evolução dos estudantes em todos os níveis do quadro. Um quadro de competências fornece, portanto, um apoio a este ideal de aprendizagem ao longo da vida, liberta das limitações restritivas das instituições. Em contrapartida, a noção de competência associada ao desenvolvimento econômico 'pós-fordista' exige um estudante flexível, sempre disposto a assumir novas oportunidades de formação. Enquanto os objetivos 'com foco no estudante' sublinham a participação e a quebra de barreiras entre professores e estudantes, a interpretação pós-fordista dos quadros baseados em resultados aponta para a necessidade de 'pacotes de formação' elaborados e sofisticados, para apoiar os estudantes a adquirirem habilidades e progredirem de 'varredores a engenheiros' - um slogan popular na África do Sul no início dos anos 1990. Ambos os conjuntos de pressupostos tornam árduas, mas muito diferentes, as reivindicações pedagógicas dos professores e assumem modelos muito diferentes de formação de professores. Nos países pobres em que os recursos são limitados, essas exigências distintas só podem gerar confusão. Além disso, em suas respectivas prioridades de libertar os estudantes para realizar suas capacidades inatas e, ao encorajá-los a adquirirem habilidades por meio de 'pacotes de formação', ambas as

24 NA: Há, claro, uma longa tradição de pesquisa remontando ao trabalho pioneiro do psicólogo histórico-cultural russo, Lev Vygotsky, que desafia essa aproximação 'psicológica' ao aprendizado, que não será discutido por estar além do escopo deste artigo. 
visões sobre competências atuam como a extensão de que o progresso a níveis mais elevados no quadro pressupõe o acesso ao conhecimento - o que não está explícito no próprio quadro.

Um dos problemas com quadros baseados em resultados que atravessam as alegações de que eles promovem justiça social e uma maior competência da força de trabalho é que eles se apresentam como 'escadas de oportunidades' para que os estudantes 'possam subir'. Entretanto, a simples ideia de um 'resultado' é retrospectiva. Ela aponta para a evidência de conquistas anteriores e não para se essas conquistas constituem a base de aprendizagem para que os estudantes avancem para um nível superior. As condições para 'subir a escada' levam-nos para além dos resultados do conhecimento que um estudante pode adquirir em um programa de estudo. Porque os quadros de competências baseados em resultados são apresentados como 'escadas de oportunidades', há o perigo de que eles conduzam à negligência das reformas necessárias mais profundas para promover oportunidades, que os níveis de um quadro de competências não pode mais fazer do que apontar.

Exemplos são a probabilidade com que os governos assegurarão o financiamento dos estudantes para o acesso à educação (uma barreira para a formação profissional em muitos países); que os empregadores concedam tempo livre pago para estudantes com emprego; e que os recursos sejam concentrados na criação ou no reforço das instituições, para aumentar a probabilidade de que elas possam permitir que os estudantes progridam.

Neste projeto, esperamos explorar como os diferentes países, ao introduzirem os quadros de competências, estão respondendo a essas visões contraditórias do que um quadro de competências pode oferecer, que tipos de compromissos são alcançados e quais são as consequências. 


\section{Conclusões}

Este documento pretende oferecer uma maneira de pensar sobre a reforma das competências e, em particular, fornecer uma base para analisar a introdução dos quadros de competências por resultados. Sugerimos que esta mudança é melhor percebida em termos de mudança de modelos de competências 'baseado nas instituições' para modelos 'baseado em resultados', e que esta mudança é passível de ter um significado totalmente diferente nos países desenvolvidos e naqueles em desenvolvimento. Neste artigo, não exploramos esta diferença em detalhe. É provável, entretanto, que o problema das competências baseadas em resultados estabelecendo um tipo de confiança que é necessária, se elas têm de atuar como mediadoras entre a educação e o trabalho -, será mais agudo nos países em desenvolvimento, sem uma tradição extensiva de programas baseados em instituições. Os primeiros exemplos dos modelos de 'resultados' apareceram, inicialmente, nos países anglófonos, como expressão das políticas de educação neoliberais e a insatisfação com a abordagem tradicional das competências 'baseada nas instituições'. Os governos, preocupados, sentiram que as competências estavam intimamente ligadas aos interesses das instituições fornecedoras, sem capacidade de resposta para as mudanças econômicas exigidas pelos empregadores ou para as necessidades de aprendizagem das quais o eleitorado mais amplo foi excluído. Países em desenvolvimento, no entanto, estão adotando os quadros baseados em resultados menos por insatisfação com os sistemas existentes - que, em alguns casos não estão bem definidos - e mais na esperança de que as competências possam conduzir à expansão dos sistemas de ensino e treinamento financiadas pelo governo, e abrindo oportunidades para o setor privado. Isso significa que, nos países em desenvolvimento, os governos estão contando com um instrumento de reforma que a experiência nos países desenvolvidos sugere que pode não dar certo. 
Nossos dois modelos ressaltam a ênfase nos quadros de competências, que é posta como "relatório de resultados", e que as competências não devem depender de qualquer instituição ou caminho de aprendizagem que possa conduzir a elas. Ao mesmo tempo, nós argumentamos que nossos dois modelos devem ser vistos como tipos ideais - isto é, como tendências nos desenvolvimentos recentes da qualificação. E não, como é tão comum na literatura, como prescrições do tipo 'tamanho único', nas quais as competências foram desenvolvidas baseadas amplamente na hipótese inquestionável de que não elas não conduzem a objetivos particulares. Nem devem ser vistas como descrições dos quadros existentes; quadros diferentes são, provavelmente, para enfatizar aspectos de cada modelo em diferentes graus.

Há dois temas deste artigo que importa tornar explícitos. O primeiro é a ênfase que demos ao papel dos empregadores (e, por implicação, o dos sindicatos, que devem ter também interesses muito diferentes daqueles dos empregadores e governos, ainda que não tenhamos lidado com eles aqui). Isso reflete o fato de que muitos QNCs começaram como quadros para competências profissionais; e, em seguida, que os objetivos econômicos mais do que os sociais foram fundamentais para que a maioria dos países introduzisse os QNCs e, além disso, muitos dos argumentos para expressar as competências em termos de 'relatórios de resultados' derivam do pressuposto de que isso vai facilitar um envolvimento maior do empregador. Até que ponto essas alegações para os quadros baseados em resultados são justificadas é uma das questões que esperamos que este projeto possa explorar.

O segundo tema do documento a ser destacado é que fomos mais explicitamente críticos no que diz respeito ao modelo 'de resultados', não por não entendermos como ele surgiu ou porque não reconhecemos as fraquezas do modelo baseado em instituições, que ele pretende substituir - nós o criticamos por uma série de outras razões. A primeira delas é que quase toda a literatura trata dos modelos de resultados como o próximo passo - quase sempre inevitável - para todos os países, e 
como uma política que irá garantir os objetivos que muitos países apoiam. Pensamos que isso não ajuda em nada, para não dizer coisa pior, especialmente para os países pobres, que têm de tomar decisões difíceis sobre em quais reformas educacionais devem investir. Ele é fundamentalmente inútil porque as evidencias vindas dos países que já introduziram os quadros de competências dificilmente justifica as hipóteses feitas a seu favor, deixando entrever que eles são uma espécie de panaceia para melhorar os sistemas de educação e de formação. Não menos importante é que a literatura quase que sistematicamente ignora as dificuldades concretas que foram enfrentadas pelos 'primeiros países', ao introduzirem os QNCs. O fato de os quadros mais folgados (como aqueles introduzidos na Escócia (Raffe 2009) - em que menos se esperou dos relatórios de resultados, que enfrentaram um mínimo de oposição e, em certo sentido, podem ser chamados de 'exitosos') -, é indicativo das lições daquilo que os países que estão começando devem aprender. Além do mais, a experiência dos 'que começaram depois' na Europa - como a Alemanha e a França - também é importante; eles explicitaram os resultados em seus novos quadros, mas eles não seguem a lógica de um modelo puro de 'resultados' e assumem que estes podem ser completamente separados do 'oferecido' pelas instituições. Dissemos no início deste artigo que não estávamos interessados em escrever somente uma nova crítica; ironicamente, esta é a razão pela qual tivemos a necessidade de levantar questões sobre as hipóteses que são tão frequentemente feitas ao modelo de resultados. A menos que seja possível identificar um espaço entre essas sugestões para os quadros de competências e o que eles podem ou não podem atingir, realisticamente falando, os países que estão começando não terão uma base confiável para decidirem sobre a implementação dos QNCs e nem para compreenderem que não há apenas 'um' modelo de QNC que deve ser aplicado em todos os casos, mas que ter somente os relatórios de resultados em um quadro não serve de antídoto. O ponto de partida precisa ser sempre uma análise das circunstâncias particulares de um país e das qualificações existentes, o que elas oferecem e como novas oportunidades podem ser abertas a partir de uma referência mais explícita aos resultados e níveis comuns. 
Somente assim será possível ver que papel os relatórios de resultados em um quadro podem desempenhar, juntamente com as - e não menos importantes - políticas de fortalecimento das instituições e o desenvolvimento profissional de professores e capacitadores, e a construção de parcerias entre educação e empregadores.

Nossa análise em dois modelos explora o equilíbrio entre a ênfase nas instituições que fornecem a base para uma alta qualidade de aprendizagem e progressão, mas que constrói essa base em uma tendência de inflexibilidade e formas de exclusão - e a ênfase nos resultados, que oferecem a possibilidade da portabilidade, transparência e flexibilidade na maneira pela qual as qualificações são obtidas; mas são essencialmente sobre os objetivos dos programas de aprendizagem, não sobre os processos envolvidos. Salvo em casos excepcionais, estas não são opções pelas quais nós subestimamos o papel potencial de um modelo 'puro' baseado em resultados no Reconhecimento do Aprendizado pela Experiência (APEL). Há situações em que o reconhecimento de uma aprendizagem informal para as qualificações pode ser importante. No entanto, parece muito pouco provável, especialmente nos países pobres, que haja recursos disponíveis para a criação da infra-estrutura que é necessária para que isso se torne uma realidade. Também é questionável se esses recursos não seriam melhor gastos ajudando pessoas a terem acesso a uma educação de qualidade. O mais realista é que as instituições sejam encorajadas e ajudadas a desenvolver cursos 'de acesso', que habilitem aqueles cujas certificações anteriores não atendam a possibilida de de ingressar em programas de nível superior.

Essas só podem ser conclusões provisórias. Estamos no início deste projeto e estamos confiantes de que, no final, devemos aprender muito sobre as diferentes formas que os quadros de competências podem assumir, e como os países resolvem o equilíbrio entre as in stituições e os resultados de maneiras tão diferentes. 


\section{Comentários finais}

Este artigo começou reconhecendo que a introdução do quadro de competências é um projeto muito mais ambicioso e radical do que a maioria dos formuladores de políticas e gestores já percebeu. Também é claro que um quadro de competências baseado em resultados provenientes da formação e da experiência - como o do tipo que foi previsto por Jessup (1990) - seja realizável ou desejável. Em alguns aspectos, quadros de competências são melhor compreendidos como utopias e, como todas elas, despertam mais atração na teoria do que na prática. Isto não significa que os quadros de competências não estão dirigidos a questões concretas; eles estão, como nós tentamos demonstrar neste artigo. Além disso, e ao contrário do que acontece com a maioria das utopias, os quadros de competências estão assumindo formas reais em um número cada vez maior de países e são essas formas, e não as visões utópicas, que fazem dos quadros de competências importantes orientadores de políticas - que estão definindo a vida das pessoas de maneira significativa, mas ainda de maneira desconhecida e que implicam importantes compromissos financeiros por parte dos governos.

A OIT desenvolveu esta pesquisa porque estava interessada em entender não somente os modelos de política que estão funcionando, mas também sob que condições eles trabalham e o que países que estão enfrentando condições muito diferentes podem aprender a partir deles. É igualmente interessante aprender sobre as políticas que não deram certo e as explicações para este fracasso - quer no nível da concepção ou da execução. Este artigo representa o primeiro dado desta pesquisa, e é escrito não porque esperamos que todos aqueles que o leiam concordem com os argumentos aqui expostos, mas na esperança de que eles provoquem um debate - e, ao fazer isso, ajudem todos os que estamos envolvidos no projeto a pensar mais claramente sobre essas questões. Esperamos também que ele sugira algumas questões que os pesquisadores dos estudos de caso possam vir a perguntar sobre o 
quadro de competências que eles estejam investigando. Alguns dos conceitos introduzidos neste artigo serão inúteis e terão de ser, descartados, sem a menor dúvida; outros serão esclarecidos no curso do debate e da discussão e, espera-se, tornem-se analiticamente mais úteis. Novos conceitos irão sem dúvida aparecer no processo de investigação e de comparação.

O desenvolvimento dos quadros de competências não é um objeto fixo de estudo, mas um fenômeno que está mudando a todo instante e de maneiras inesperadas. O pressuposto é o de que não começamos do zero. Há alguns padrões que surgiram e podem surgir de novo e temos alguns conceitos, baseados nas experiências dos quadros de competências dos 'que iniciaram primeiro' que nos permitem levantar perguntas que não têm apenas respostas descritivas. Ao mesmo tempo, descrições dos novos casos serão a nossa principal matéria-prima para desenvolver uma melhor compreensão das possibilidades e das limitações da introdução dos quadros de competências. Portanto, por favor, tratem os argumentos deste artigo tão criticamente como nós tratamos algumas das hipóteses sobre os quadros de competências. E os testem onde puderem contra sua própria experiência, contra qualquer evidencia (contrária) que apareça em seu país e contra quaisquer outros argumentos que encontrarem. Desta forma, talvez estejamos em uma posição mais fortalecida ao final do projeto para indicar provavelmente impasses, e aconselhar sobre alternativas a serem construídas.

Quadros de competências e seus equivalentes internacionais, como o Quadro Europeu de Qualificação (EQF), não desaparecerão; eles representam, sem dúvida, verdadeiras mudanças no mundo. O mundo está ficando menor e não maior, no que diz respeito à nossa interdependência, e como as empresas procuram novos locais para seus lucros, uma maior e não menor mobilidade do trabalho é provável, já que os padrões de migração mudam sempre em resposta às economias cada vez mais instáveis. Quadros nacionais e regionais, apesar de todos os seus problemas, são 
tentativas de levar em consideração essas mudanças; precisamos saber mais sobre como os quadros aparentemente semelhantes diferem, na prática. Em particular, estamos interessados em uma diferença específica entre os países. Entre aqueles que estão usando o quadro de competências principalmente para coordenar e racionalizar relativamente bem os sistemas de educação e de formação já desenvolvidos; e aqueles que estão introduzindo um quadro de competências como uma maneira de estimular o desenvolvimento de seus sistemas de educação e de formação - e como uma maneira de compensar as grandes camadas da população que não têm acesso às oferta de educação in stitucionalizada ${ }^{25}$.

Contatos

Por favor, envie quaisquer reações, perguntas, críticas, comentários e sugestões, sejam eles curtos ou longos, para Stephanie Allais (allais@ilo.org) e Michael Young (m_young@ioe.ac.uk).

\section{Reconhecimentos}

Obrigado a Christopher Winch, Christine Evans-Klock, David Raffe, Leesa Wheelahan e Rob Strathdee pelos comentários perspicazes/inteligentes e críticas das versões anteriores deste artigo.

$25 \quad$ NA: Há outras questões para as quais este artigo não se dirige, e nas quais esperamos nos envolver no curso do projeto. Duas foram fortemente citadas aqui: o papel dos fornecedores privados algo que provavelmente terá significado considerável nos paises em desenvolvimento; o papel do financiamento, e como e quando governos utilizam os quadros de competências como base para financiamento, isto influencia o papel dos quadros de competências. 


\section{Bibliografia}

Allais, S. (2007). The Rise and Fall of the NQF: A critical analysis of the South African National Qualifications Framework. Doctoral thesis. University of the Witwatersrand

Bond, P. 2005. Neoliberalism in Sub-Saharan Africa: From Structural Adjustment to NEPAD. In Neoliberalism: A Critical Reader, edited by A. Saad-Filho and D. Johnston. London: Pluto Press.

Brockmann, M., with L. Clarke, and C. Winch. 'Can performance-related learning outcomes have stan dards?'. Journal of European Industrial Training. 32(2/3). pp.99-113.

CEDEFOP. (2008). The Shift to Learning Outcomes: Conceptual, political and practical developments in Europe. Luxembourg, Office for Official Publications of the European Communities.

Coles, M. (2007). Qualifications frameworks in Europe: platforms for collaboration, integration and reform. Presidency Conference 'Realizing the European Learning Area'/ Munich, 4 - 5 June 2007.

Collins, R. (1979). The Credential Societj: An Historical Sociologj of Education and Stratification, Academic Press.

Dore, R. (1976). The Diploma Disease: Education, Qualifications and Development. London: Allen and Unwin.

Dumenil, G, and D. Levy. 2005. The Neoliberal (Counter-) Revolution. In Neoliberalism: A Critical Reader, edited by A. Saad-Filho and D. Johnston. London: Pluto Press. 
Gallagher, J. (2006) 'Blurring the boundaries or creating diversity: the contribution of the further education colleges to higher education in Scotland'. Journal of Further and Higher Education. 30(1).

Grubb, N, and M. Lazerson. 2006. The Globalization of Rhetoric and Practice: The Education Gospel and Vocationalism. In Education, Globalization, and Social Change, edited by H. Lauder, P. Brown, J. Dillabough and A. H. Halsey. Oxford: Oxford University Press.

Harvey, D. 2000. Spaces of Hope. Berkeley: University of California.

Press.

Habermas, J. (1975). Legitimation Crisis. Boston: Beacon.

International Labour Organization. (2008). Report V: Skills for Improved Productivity, Employment Growth, and Development. International Labour Conference, $97^{\text {th }}$ Session. Geneva: International Labour Office.

Muller, J. (2000). Reclaiming Knowledge. London and New York: RoutledgeFalmer.

Palley, Thomas I. 2005. From Kenynesianism to Neoliberalism: Shifting Paradigms in Economics. In Neoliberalism: A Critical Reader, edited by A. SaadFilho and D. Johnston. London: Pluto Press.

Phillips, D. J. 1998. The switchment of history: the development of a unitary qualifications framew ork. Doctoral thesis, University of Wellington, Victoria.

Raffe, D. (2009, forthcoming). 'The Action Plan, Scotland and the Making of the Modern Educational World: The First Quarter Century'. Scottish Educational Review. 41(1).

Raggatt, P. and Williams, C. (1990). Government, markets and vocational qualifications: an 
anatomj of policj. Falmer Press, London.

West, J. (2004). Nightmares and dreams: the NVQ experience. Centre for Labour Market Studies, University of Leicester, Working Paper 45.

Wolf, A. (2002). Does Education Matter? Mjths about education and economic growth. London, Penguin.

Young, M. (2007). Bringing Knowledge Back In. London, Routledge.

Young, M. (2009). 'What are schools for?' in Knowledge, Values, and Educational Policj. H. Daniels, H. Lauder, and J. Porter (eds).

Winch, C. with Michaela Brockmann, Linda Clarke. (forthcoming, 2008). 'Knowledge, Skills, Competence: European Divergences in Vocational Education and Training (VET) - the English German and Dutch cases.' Oxford Review of Education.

Winch, C. \& Clarke, L (2006). 'A European Skills Framework: but what are skills?'. Journal of Education and Work, 19 (3). pp. 255-269. 